\title{
IMPACT OF MULTI-WALLED CARBON NANOTUBES ON WOOD SAWDUST EXTRACT CEMENT MORTAR
}

\author{
Ekaterina KARPOVA ${ }^{1 *}$, Gintautas SKRIPKIŪNAS ${ }^{1}$, Grigory YAKOVLEV ${ }^{2}$, Asta KIČAITE் ${ }^{1}$ \\ ${ }^{1}$ Faculty of Civil Engineering, Vilnius Gediminas Technical University, Vilnius, Lithuania \\ ${ }^{2}$ Faculty of Civil Engineering, Kalashnikov Izhevsk State Technical University, Izhevsk, Russia
}

Received 7 January 2020; accepted 25 March 2020

\begin{abstract}
It is well known that organic waste materials deteriorate the performance of concrete. The impregnation of organic aggregates and their application in combination with other chemical admixtures and mineral additives are used in order to improve the concrete properties in case of their modification by organic components. The current research is focused on the evaluation of impact of multi-walled carbon nanotubes (MWCNT) on the properties of cement systems prepared based on wood sawdust extract (WSE). The setting time, density, consistency, flexural and compressive strength, water absorption tests were undertaken. The retardation effect of (WSE) on the initial and final setting time of cement paste was observed. The additional modification of cement paste with WSE by MWCNT in the dosage of $0.005 \%$ by weight of cement (bwoc) did not show the significant changes in initial and final setting time. The application of MWCNT in the dosage of $0.005 \%$ bwoc contributed to the increase of early strength of cement mortar prepared with WSE.
\end{abstract}

Keywords: waste materials, concrete, nanomodification, carbon nanotubes.

\section{Introduction}

The problem of the utilization of waste materials is becoming more relevant from year to year caused by industrial growth. The one way to solve this problem consists in the application of agricultural, industrial and municipal wastes for production of green concrete (Liew et al., 2017). The waste materials can replace the cement and aggregates in ordinary concrete. The number of researches demonstrate the successful usage of wastes and confirm the potential of their further development in the construction industry. The authors of the study (Ossa et al., 2016) demonstrated the use of construction and demolition waste aggregates in percentage up to $20 \%$ for paving urban roads. Reference (Corinaldesi, 2010) confirms the feasibility to produce the structural concrete by replacing $30 \%$ of ordinary aggregates with recycled rubble obtained from demolition. The researches (Bajare et al., 2013) examined the possibilities to reuse non-metallic product from aluminium scrap recycling factories for the production of lightweight expanded clay aggregates and lightweight concrete.

Moreover, agricultural wastes can be used for the production of green concrete (Boltryk et al., 2018; Ramos et al., 2013; Sosoi et al., 2018). The authors of the research Boltryk et al. (2018) highlight the ability of organic ma- terials to absorb carbon dioxide from the atmosphere. They established that the usage of mineralized organic aggregates such as common reed and conifer sawdust leads to the increase of the calcium carbonate by $45 \%$ in comparison to reference samples. The replacement of traditional aggregates by sawdust increases the thermal properties and reduces the mechanical properties of concrete (Memon et al., 2017; Aigbomian \& Fan, 2013; Cheng et al., 2013; Madrid et al., 2018).

Wood sawdust (WS) has the organic origin and comprises of cellulose, hemicellulose and lignin which have hydroxyl groups (-OH) (Ahmed, 2018).

The presence of organic molecules promotes the retardation effects and decrease of the strength parameters of cement composites at early ages (Mishra et al., 2003; Gil et al., 2017). The organic molecules adsorb by hydrogen bonding via their hydroxyl groups. The polar and hygroscopic nature of hydroxyl groups hinder the water, which is available for the hydration of silicate and, as a consequence, leads to the retardation effects and decrease of early strength (Mishra et al., 2003).

The different types of treatment are used to improve the properties of the organic aggregates (Bederina et al.,

${ }^{*}$ Corresponding author. E-mail: ekaterina.karpova@vgtu.lt 
2012; Aigbomian \& Fan, 2014). The oil impregnation of wood shavings showed better effectiveness during an investigation of wood sand concrete (Bederina et al., 2012).

With the development of nanotechnology, the application of nanoparticles has a considerable perspective on the improvement of green concrete properties due to their ability to accelerate the hydration processes and influence on the concrete microstructure (Vishwakarma \& Ramachandran, 2018). The numbers of investigation are devoted to the study of nanoparticles, such as nanoclays, calcium carbonate nanoparticles, nano silica and some others, which demonstrate the significant influence on the cement matrix with an introduction in small dosages (Kawashima et al., 2013; Wu et al., 2016; Zhang et al., 2017). The huge interest of researches is paid to the modification of cement composites by carbon nanotubes (CNT) of different types (Han et al., 2013; Isfahani et al., 2016; Sobolkina et al., 2012).

In the course of the current research, the effect of multi-walled carbon nanotubes (MWCNT) on the cement paste and mortar based on wood sawdust extract (WSE) was studied through setting time, consistency, density, strength and water absorption tests.

\section{Experimental program}

\subsection{Materials}

The cement CEM I $42.5 \mathrm{R}$ (supplied by AB "Akmenes Cementas") conforming to EN 197-1 (European Committee for Standardization [CEN], 2012) was used as a binder. The mineral composition of the main cement clinker minerals is presented in Table 1. The physical and mechanical properties of the cement are listed in Table 2.

Table 1. Mineral composition of the cement clinker

\begin{tabular}{|l|c|}
\hline \multicolumn{1}{|c|}{ Component } & Amount, $\%$ \\
\hline Tricalcium silicate $\left(\mathrm{C}_{3} \mathrm{~S}\right)$ & 57.9 \\
\hline Dicalcium silicate $\left(\mathrm{C}_{2} \mathrm{~S}\right)$ & 15.6 \\
\hline Tricalcium aluminate $\left(\mathrm{C}_{3} \mathrm{~A}\right)$ & 7.5 \\
\hline Tetracalcium aluminoferrite $\left(\mathrm{C}_{4} \mathrm{AF}\right)$ & 11.9 \\
\hline
\end{tabular}

Table 2. Physical and mechanical properties of the cement

\begin{tabular}{|l|c|}
\hline \multicolumn{1}{|c|}{ Property } & Value \\
\hline 2-day compressive strength, $\mathrm{MPa}$ & $28 \pm 2$ \\
\hline 28-day compressive strength, $\mathrm{MPa}$ & $55 \pm 3$ \\
\hline Initial setting time, min & 160 \\
\hline Final setting time, min & 180 \\
\hline Volume stability, $\mathrm{mm}$ & 1.0 \\
\hline Water consumption, \% & 26.6 \\
\hline Residue on the $90 \mu \mathrm{m}$ sieve, $\%$ & 1.5 \\
\hline Specific surface, $\mathrm{cm}^{2} / \mathrm{g}$ & 4000 \\
\hline
\end{tabular}

The sand fraction of $0 / 4 \mathrm{~mm}$ was applied as a fine aggregate conforming to the requirements of EN 12620.

Due to the fact that cement hydration is mainly determined by the composition of liquid phase, the WS aggregates were not used in the course of experiments. WSE water was prepared by the immersion of WS in water during $24 \mathrm{~h}$. WS with an average particle size of $5 \mathrm{~mm}$ was applied to obtain WSE water. The ratio between WS and potable water was equal to 1:6. The time of WS immersion of $24 \mathrm{~h}$ was taken according to the typical time of wetting of aggregates by water in concrete technology. The potable water according to EN 1008 (CEN, 2005) was used during experiments.

In the experiments, the nanomodification was provided by an aqueous suspension "Fulvek 100" produced by the company "Novyj dom"' (Izhevsk, Russia). The aqueous suspension "Fulvek 100" was prepared from the masterbatch pellets "Graphistrength CW 2-45" produced by the company "Arkema" (Colombes, France). The pellet contains 45 wt. \% of MWCNT and 55 wt. \% of carboxymethylcellulose (CMC). The MWCNT was characterized by filament length of $0.1-10 \mu \mathrm{m}$ and diameter of $15-20 \mathrm{~nm}$. The concentration of "Graphistrength CW 2-45" in the suspension was equal to $4.5 \%$. The homogenization of MWCNT was performed by using high-speed bead mill mixer for 2 hours. Subsequently, the suspension was subjected to ultrasonication treatment for $3 \mathrm{~min}$.

\subsection{Test methods}

The cement pastes and cement mortar based on WSE water with and without MWCNT suspension were prepared to evaluate the effect of MWCNT on the hydration of cement systems with organic aggregates and mechanical and physical properties. The setting time test was carried out according to EN 480-2 (CEN, 2007). The cement pastes with water to cement ratio of 0.275 were prepared. The determination of setting time was performed using the standard Vicat apparatus. The temperature was $20 \pm 2{ }^{\circ} \mathrm{C}$ during the test.

The mix design of tested cement mortars is presented in Table 3. The consistency test of cement mortars was performed by flow table according to the standard methodology described in EN 1015-3 (CEN, 2004a).

The standard prisms of size $40 \times 40 \times 160 \mathrm{~mm}$ for determining the density, flexural and compressive strength, water absorption were prepared with reference to EN 196-1 (CEN, 2016).

The density and strength of cement mortar were tested according to EN 1015-10, EN 1015-11 (CEN, 2004b, 2020 ), respectively. The compression testing machine Tinius Olsen $200 \mathrm{KU}$ was used to determine the compressive and flexural strength of cement mortar.

The water absorption test was performed through the immersion of cement mortar samples for 5, 30, 60, 1140 and $2880 \mathrm{~min}$ with their further weighing. 
Table 3. Mix design of the tested cement mortars

\begin{tabular}{|c|c|c|c|c|}
\hline Sample & Cement/Sand ratio & Water/Cement ratio & MWCNT, \% bwoc & Type of Water \\
\hline PW & $1: 3$ & 0.50 & 0 & potable water \\
\hline NPW & $1: 3$ & 0.50 & 0.005 & potable water \\
\hline SDW & $1: 3$ & 0.50 & 0 & WSE water \\
\hline NSDW & $1: 3$ & 0.50 & 0.005 & WSE water \\
\hline
\end{tabular}

Scanning electron microscopy (SEM) MIRA 3 Tescan was used to observe the MWCNT in hardened cement paste. The cement paste with water to cement ratio of 0.50 was mixed for better observation of MWCNT in the cement matrix. The hardened cement pastes were cured for 3 days at the temperature of $20 \pm 2{ }^{\circ} \mathrm{C}$ in a water bath. The samples after curing were crushed and prepared for SEM.

\section{Results and discussion}

\subsection{Setting time test of cement paste}

The results of setting time test of cement pastes are presented in Figure 1. The initial setting time of cement pastes prepared with WSE water (SDW) increased by 20 min in comparison with cement pastes based on potable water $(\mathrm{PW})$.

The additional modification of SDW cement paste by MWCNT suspension did not show significant changes in initial setting time. The final setting time of cement pastes with WSE (SDW) increased by $15 \mathrm{~min}$ in comparison with PW cement paste. The addition of MWCNT did not lead to the changes in final setting time.

The obtained results can be explained by the ability of organic components of WS, to adsorb water, which is needed for cement hydration (Mishra et al., 2003).

\subsection{Properties of cement mortar in fresh and hardened state}

The consistency test of cement mortar with WSE identified the slight increase of workability of cement mortar. The usage of MWCNT in the dosage of $0.005 \%$ bwoc with and without WSE did not change the consistency of cement mortar. The results of the consistency test are presented in Figure 2.

The density of cement mortar with WSE did not changed significantly in comparison with cement mortar prepared based on the potable water. The results of the density test are shown in Figure 3. The density of PW and SDW cement mortar slightly increased by $51 \mathrm{~kg} / \mathrm{m}^{3}$ and $19 \mathrm{~kg} / \mathrm{m}^{3}$, respectively, with modification by MWCNT suspension.

Figures 4 and 5 present the results of flexural and compressive strength test of cement mortar after 7 and 28 days, respectively. The flexural strength of SDW cement mortar decreased by $18.2 \%$ in comparison with PW cement mortar at 7 days age. The addition of MWCNT suspension led to the compensation of the negative impact of WSE water and increased the flexural strength up to $6.20 \mathrm{MPa}$.

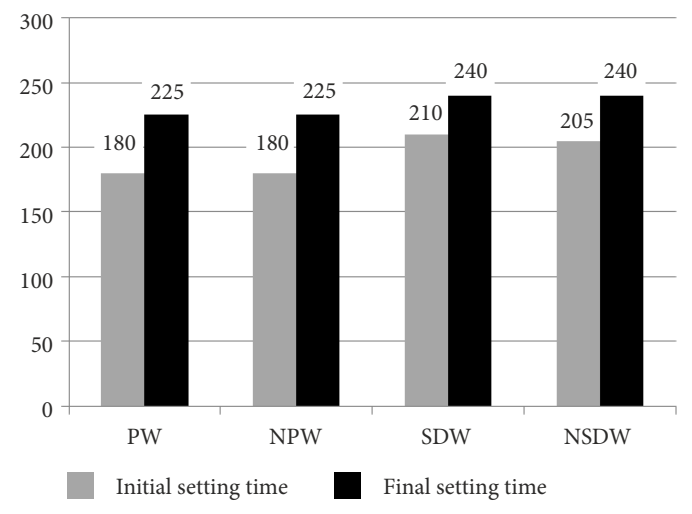

Figure 1. Initial and final setting time of cement paste

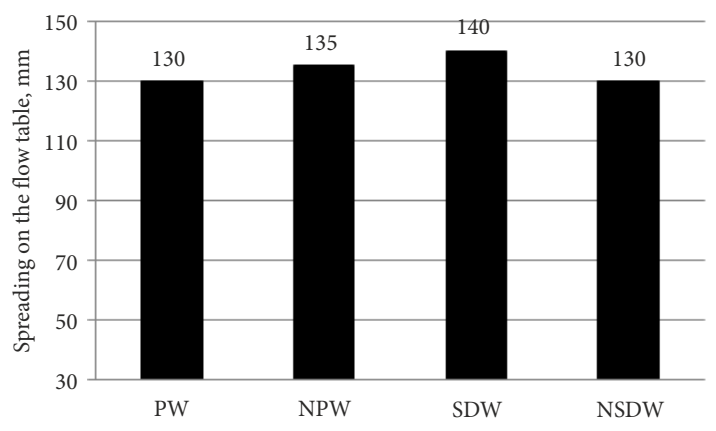

Figure 2. Consistency test of cement mortars

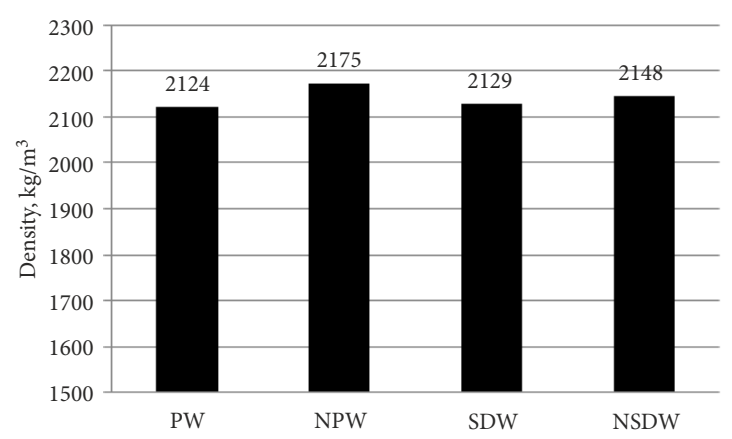

Figure 3. Density of cement mortar

The compressive strength of SDW cement mortar decreased by $13.0 \%$ at 7 days age in comparison with the PW cement mortar. The MWCNT suspension compensated the negative impact of WSE on the early compressive strength. The compressive strength of cement mortar with MWCNT (NSDW) was increased by $17.7 \%$ at 7 days in comparison with SDW cement mortar. The significant changes of flexural and compressive strength of cement mortar at 28 days age was not observed during the research. 


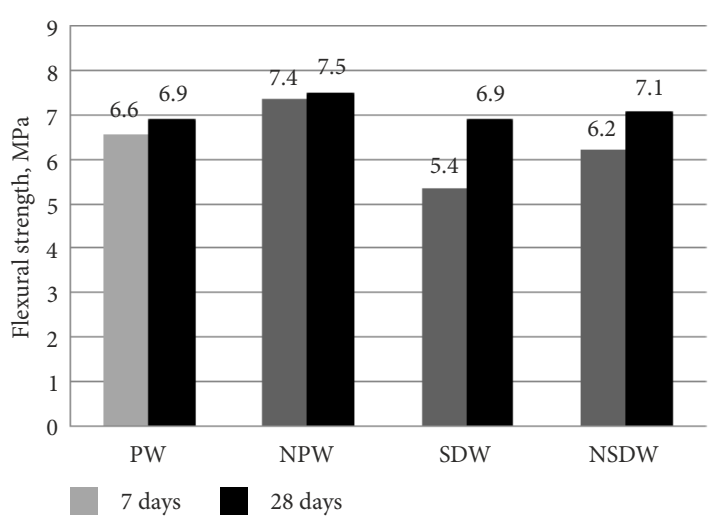

Figure 4. Flexural strength of cement mortar

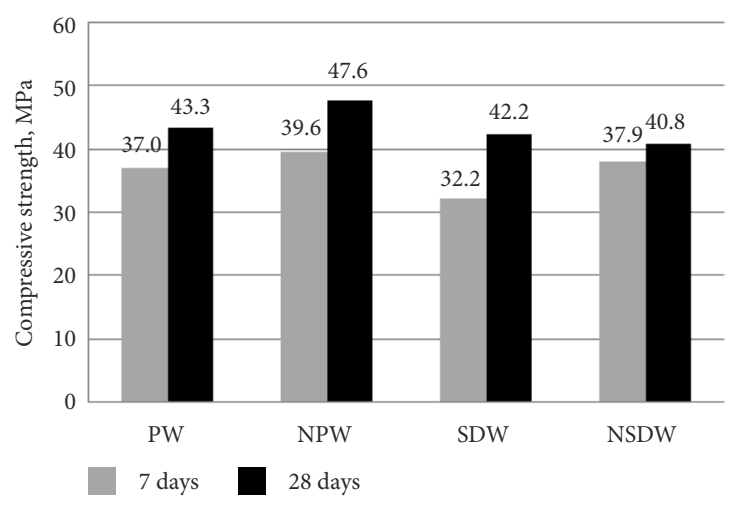

Figure 5. Compressive strength of cement mortar

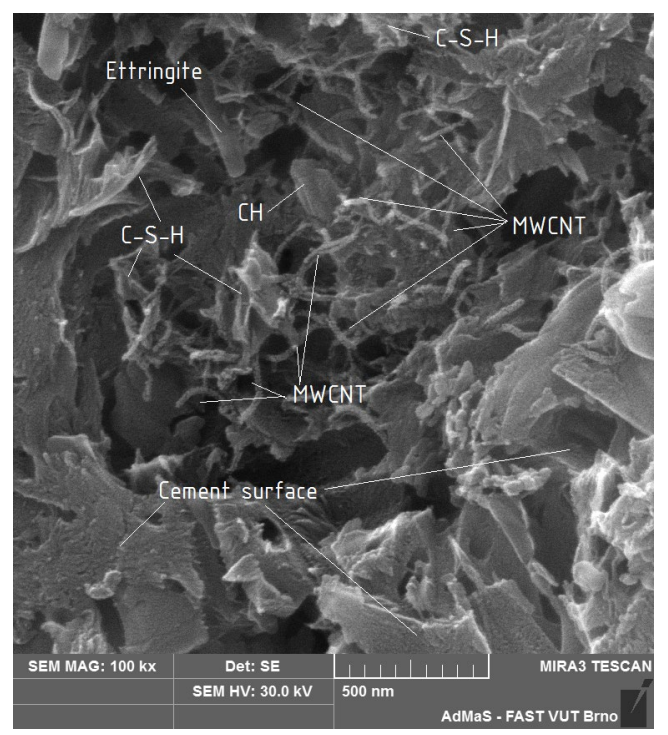

Figure 6. SEM image of MWCNT enhanced hardened cement paste

The evaluation of morphology of hardened cement paste with introduction of MWCNT was provided by SEM (Figure 6).

As it is seen in Figure 6, MWCNT located among C-S-H, $\mathrm{CH}$ and ettringite of hardened cement paste. The presence of MWCNT changes the morphology of cement hydration due to their presence in the hydration process before the appearance of cement hydration products.

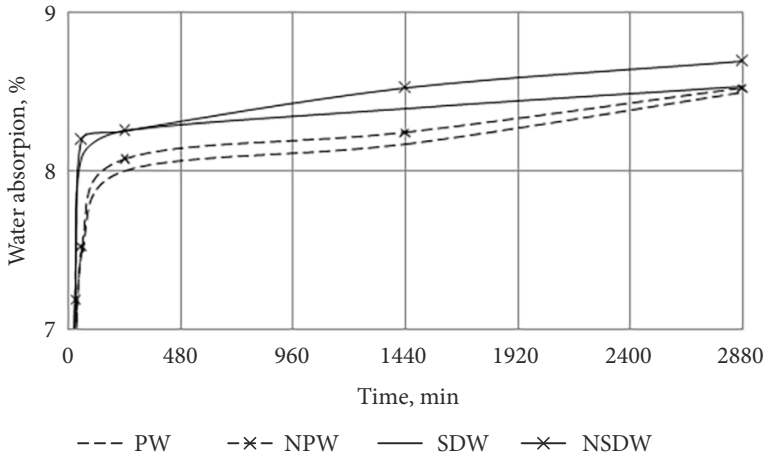

Figure 7. Water absorption of cement mortar

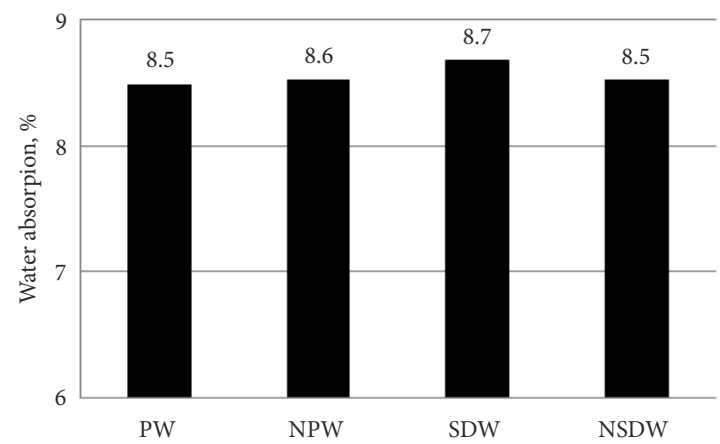

Figure 8. Total water absorption of cement mortar

In addition to density and strength properties testing, the water absorption test of cement mortars was undertaken. The results of water absorption test are presented in Figure 7. The water absorption measurements were performed at 5, 30, 60, 1440 and $2880 \mathrm{~min}$.

Figure 7 demonstrates that the water absorption of samples prepared with WSE (SDW, NSDW) slightly increases. Figure 8 presents the results of water absorption after 2 days of storage samples in the water bath. The additional modification of cement mortar with WSE by MWCNT in the dosage of $0.005 \%$ bwoc did not lead to the changes in water absorption. As a small particles, MWCNT posses by high specific surface area which contributes to high water adsorption properties. The presence of carboxymethyl cellulose used as a dispersing agent for MWCNT homogenization in the aqueous suspension and its chemical affinity to organic components of WSE can intensify the process of bonding of organic molecules by MWCNT. The bonding of organic components by MWCNT enables to decrease their adsorption on the cement hydration products and, as a consequence, to increase the amount of water, which is needed for cement hydration.

\section{Conclusions}

The following conclusions are drawn in this study:

1. The initial setting time of cement pastes with wood sawdust extract increased by $20 \mathrm{~min}$ in comparison with the reference sample prepared based on potable water. The additional modification of cement paste by MWCNT suspension did not lead to the significant changes in initial and final setting time. 
2. Wood sawdust extract does not change the consistency of cement mortar significantly and does not have a significant impact on the density of cement mortar.

3. Wood sawdust extract decrease the flexural and compressive strength of cement mortar at 7 days age by $18.2 \%$ and $13.0 \%$, respectively, in comparison with cement mortar prepared based on potable water. The application of MWCNT in the dosage of $0.005 \%$ enables to compensate for the negative effect of wood sawdust extract on early age strength.

4. The water absorption of cement mortar based on wood sawdust extract with additional modification by MWCNT was not changed.

5. The small size of MWCNT, their high surface area lead the adsorption of organic components of wood sawdust extract and, as consequence, enable to decrease the negative impact of organic components of wood sawdust on cement hydration and hardening kinetics.

\section{References}

Ahmed, W., Khushnood, R. A., Memon, S. A., Ahmad, S., Baloch, W. L., \& Usman, M. (2018). Effective use of sawdust for the production of eco-friendly and thermal-energy efficient normal weight and lightweight concretes with tailored fracture properties. Journal of Cleaner Production, 184, 10161027. https://doi.org/10.1016/j.jclepro.2018.03.009

Aigbomian, E. P., \& Fan, M. (2013). Development of wood-crete building materials from sawdust and waste paper. Construction and Building Materials, 40, 361-366.

https://doi.org/10.1016/j.conbuildmat.2012.11.018

Aigbomian, E. P., \& Fan, M. (2014). Development of wood-crete from treated sawdust. Construction and Building Materials, 52, 353-360. https://doi.org/10.1016/j.conbuildmat.2013.11.025

Bajare, D., Kazjonovs, J., \& Korjakins, A. (2013). Lightweight concrete with aggregates made by using industrial waste. Journal of Sustainable Architecture and Civil Engineering, 4(5), 67-73. https://doi.org/10.5755/j01.sace.4.5.4188

Bederina, M., Gotteicha, M., Belhadj, B., Dheily, R. M., Khenfer, M. M., \& Queneudec, M. (2012). Drying shrinkage studies of wood sand concrete - Effect of different wood treatments. Construction and Building Materials, 36, 1066-1075. https://doi.org/10.1016/j.conbuildmat.2012.06.010

Boltryk, M., Krupa, A., \& Pawluczuk, E. (2018). Modification of the properties of the cement composites with the organic filler. Construction and Building Materials, 167, 143-153. https://doi.org/10.1016/j.conbuildmat.2018.02.025

Cheng, Y., You, W., Zhang, C., Li, H., \& Hu, J. (2013). The implementation of waste sawdust in concrete. Engineering, 5, 943-947. https://doi.org/10.4236/eng.2013.512115

Corinaldesi, V. (2010). Mechanical and elastic behaviour of concretes made of recycled-concrete coarse aggregates. Construction and Building Materials, 24, 1616-1620. https://doi.org/10.1016/j.conbuildmat.2010.02.031

European Committee for Standardization. (2016). Methods of testing cement - Part 1: Determination of strength. (EN 196-1). Brussels, Belgium.

European Committee for Standardization. (2012). Cement - Part 1: Composition, specifications and conformity criteria for common cements. (EN 197-1). Brussels, Belgium.
European Committee for Standardization. (2007). Admixtures for concrete, mortar and grout - Test methods - Part 2: Determination of setting time. (EN 480-2). Brussels, Belgium.

European Committee for Standardization. (2005). Mixing water for concrete - Specification for sampling, testing and assessing the suitability of water, including water recovered from processes in the concrete industry, as mixing water for concrete. (EN 1008). Brussels, Belgium.

European Committee for Standardization. (2004a). Methods of test for mortar for masonry - Part 3: Determination of consistence of fresh mortar (by flow table) (EN 1015-3). Brussels, Belgium.

European Committee for Standardization. (2004b). Methods of test for mortar for masonry - Part 10: Determination of dry bulk density of hardened mortar. (EN 1015-10). Brussels, Belgium.

European Committee for Standardization. (2020). Methods of test for mortar for masonry - Part 11: Determination of flexural and compressive strength of hardened mortar (EN 1015-11). Brussels, Belgium.

Gil, H., Ortega, A., \& Perez, J. (2017). Mechanical behavior of mortar reinforced with sawdust waste. Procedia Engineering, 200, 325-332. https://doi.org/10.1016/j.proeng.2017.07.046

Han, B., Yang, Z., Shi, X., \& Yu, X. (2013). Transport properties of carbon-nanotube/cement composites. Journal of Materials Engineering and Performance, 22(1), 184-189. https://doi.org/10.1007/s11665-012-0228-x

Isfahani, F. T., Li, W., \& Redaelli, E. (2016). Dispersion of multiwalled carbon nanotubes and its effects on the properties of cement composites. Cement and Concrete Composites, 74, 154-163. https://doi.org/10.1016/j.cemconcomp.2016.09.007

Kawashima, S., Hou, P., Corr, D. J., \& Shah, S. P. (2013). Modification of cement-based materials with nanoparticles. Cement and Concrete Composites, 36, 8-15.

https://doi.org/10.1016/j.cemconcomp.2012.06.012

Liew, K. M., Sojobi, A. O., \& Zhang, L. W. (2017). Green concrete: Prospects and challenges. Construction and Building Materials, 156, 1063-1095.

https://doi.org/10.1016/j.conbuildmat.2017.09.008

Madrid, M., Orbe, A., Carre, H., \& Garcia, Y. (2018). Thermal performance of sawdust and lime-mud concrete masonry units. Construction and Building Materials, 169, 113-123. https://doi.org/10.1016/j.conbuildmat.2018.02.193

Memon, R. P., Mohd. Sam, A. R., Abdul Awal, A. S. M., \& Achekzai, L. (2017). Mechanical and thermal properties of sawdust concrete. Sciences and Engineering, 79(6), 23-27. https://doi.org/10.11113/jt.v79.9341

Mishra, P. C., Singh, V. K., Narang, K. K., \& Singh, N. K. (2003). Effect of carboxymethyl-cellulose on the properties of cement. Materials Science and Engineering: A, 357(1-2), 13-19. https://doi.org/10.1016/S0921-5093(02)00832-8

Ossa, A., Garcia, J. L., \& Botero, E. (2016). Use of recycled construction and demolition waste (CDW) aggregates: A sustainable alternative for the pavement construction industry. Journal of Cleaner Production, 135, 379-386. https://doi.org/10.1016/j.jclepro.2016.06.088

Ramos, T., Matos, A. M., \& Sousa-Coutinho, J. (2013). Mortar with wood waste ash: Mechanical strength carbonation resistance and ASR expansion. Construction and Building Materials, 49, 343-351.

https://doi.org/10.1016/j.conbuildmat.2013.08.026

Sobolkina, A., Mechtcherine, V., Khavrus, V., Maier, D., Mende, M., Ritschel, M., \& Leonhardt, A. (2012). Dispersion of carbon nanotubes and its influence on the mechanical properties 
of the cement matrix. Cement and Concrete Composites, 34, 1104-1113.

https://doi.org/10.1016/j.cemconcomp.2012.07.008

Sosoi, G., Barbuta, M., Serbanoiu, A. A., Babor, D., \& Burlacu, A. (2018). Wastes as aggregate substitution in polymer concrete. Procedia Manufacturing, 22, 347-351.

https://doi.org/10.1016/j.promfg.2018.03.052

Vishwakarma, V., \& Ramachandran, D. (2018). Green Concrete mix using solid waste and nanoparticles as alternatives - A review. Construction and Building Materials, 162, 96-103. https://doi.org/10.1016/j.conbuildmat.2017.11.174

Wu, Z., Shi, C., Khayat, K. H., \& Wan, S. (2016). Effects of different nanomaterials on hardening and performance of ultrahigh strength concrete (UHSC). Cement and Concrete Composites, 70, 24-34.

https://doi.org/10.1016/j.cemconcomp.2016.03.003

Zhang, P., Wan, J., Wang, K., \& Li, Q. (2017). Influence of nano$\mathrm{SiO}_{2}$ on properties of fresh and hardened high performance concrete: A state-of-the-art review. Construction and Building Materials, 148, 648-658.

https://doi.org/10.1016/j.conbuildmat.2017.05.059 